\title{
CORRIGENDUM
}

\section{Waist circumference and body mass index in Chinese children: cutoff values for predicting cardiovascular risk factors}

RYT Sung, CCW Yu, KC Choi, A McManus, AMC Li, SLY Xu, D Chan, AFC Lo, JCN Chan and TF Fok International Journal of Obesity (2007) 31, 567. doi:10.1038/sj.ijo.0803540

Correction to: International Journal of Obesity (2007) 31, 550-558. doi:10.1038/sj.ijo.0803452

Since the above publication the authors have noticed an error in the legend of Figure 3. The following sentence
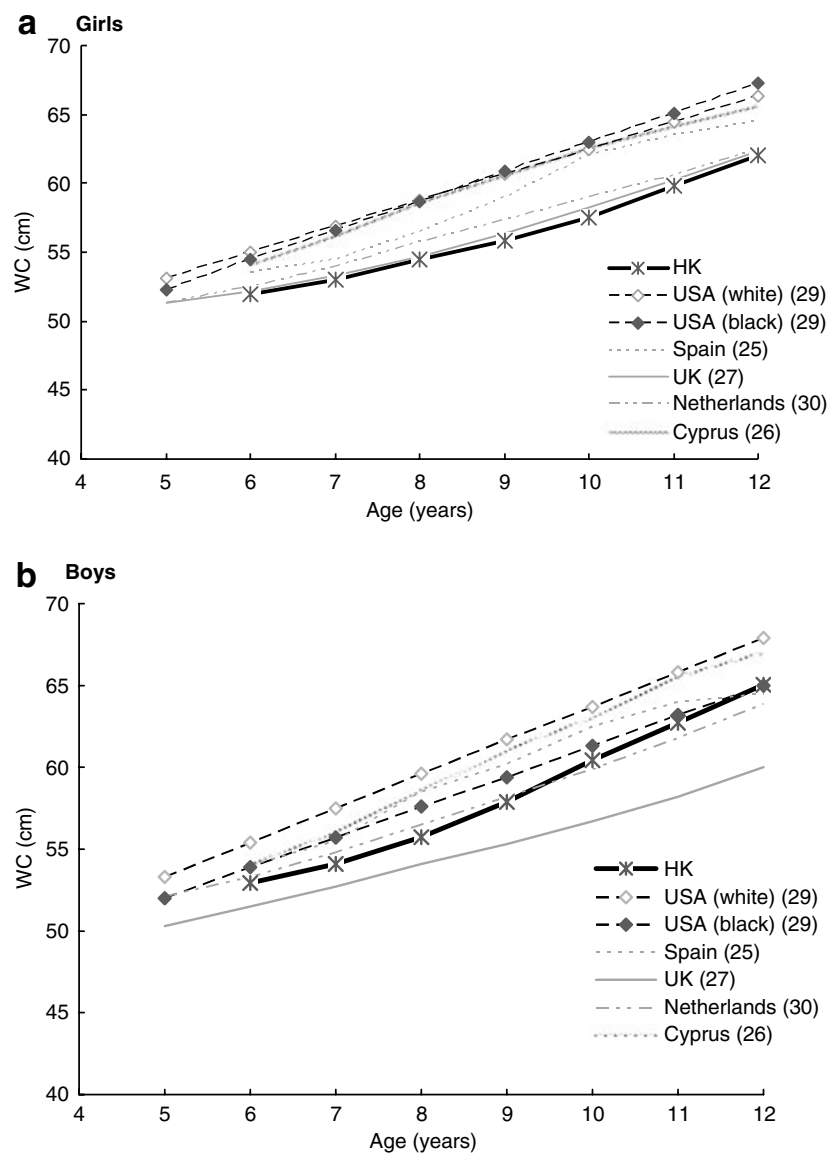

Figure 3 50th percentile for WC. (a) Girls and (b) boys. should appear in the legend of Figure 4, 'Bogalusa data (US White and US Black) and HK (Chinese) data from the present study-both using three of the six risk factors and other quintiles'.

The correct versions of Figure 3 and Figure 4 and their legends are shown here:
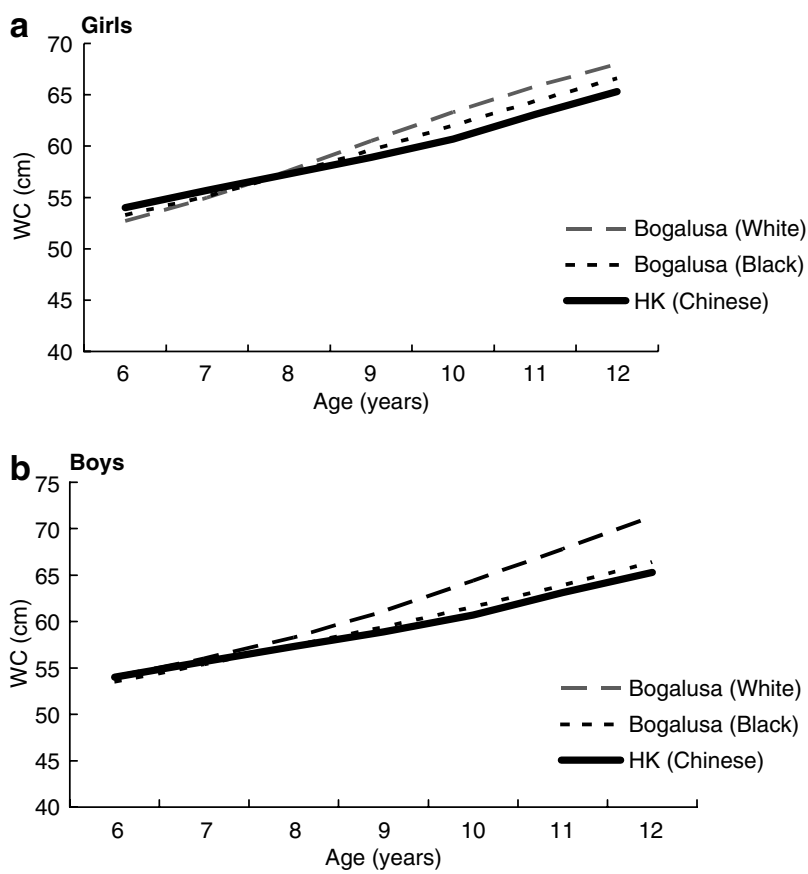

Figure 4 WC thresholds for predicting high CV risk (a) girls and (b) boys. Bogalusa data (US White and US Black) ${ }^{34}$ and HK (Chinese) data from the present study-both using three of the six risk factors and outer quintiles. 